\title{
M1 or M2: Which Is the Better Monetary Target?
}

\author{
DALLAS S. BATTEN and DANIEL L. THORNTON
}

\begin{abstract}
$\mathrm{T}$ HE past few years have been marked by financial innovation and deregulation: the rapid growth of money market mutual funds (MMMFs), the nationwide introduction of NOW accounts (January 1, 1981), the introduction of tax-exempt, all-savers certificates (October 1, 1981) and, most recently, the introduction of the Garn-St Germain money market deposit accounts (December 14, 1982) and super-NOW accounts (January 5,1983$)^{1}{ }^{1}$ These changes have led the Federal Open Market Committee (FOMC) to alter the relative weight given to $\mathrm{M} 1$ and $\mathrm{M} 2$ in its policy deliberations during the past two years.
\end{abstract}

In 1981, the rapid growth of all-savers certificates prompted the FOMC to lessen the weight assigned to the M1 target relative to the broader monetary aggregate. ${ }^{2}$ More recently, the large volume of maturing all-savers certificates and the anticipated introduction of the new money market deposit accounts (MMDAs) prompted the FOMC to give much less weight to $\mathrm{Ml}$ at its October 1982 meeting. ${ }^{3}$ Many believe that these regulatory changes and financial innovations have increased the substitutability between MI and non-MI financial assets, thereby weakening the link between the narrow monetary aggregate and economic activity.

\footnotetext{
${ }^{1}$ For a discussion of these developments, see Daniel L. Thornton, "The FOMC it 1981: Monetary Control in a Changing Financial Environment," this Review (April 1982), pp. 3-22; John A. Tatom, "Recent Financial Innovations: Have They Distorted the Meaning of M l?" this Review (April 1982), pp. 23-35; and John A. Tatom, "Money Market Deposit Accounts, Super-NOWs and Monetary Policy," this Review (March 1983), pp. 5-16.

${ }^{2}$ See Thornton, "The FOMC in 1981," p. 15.

${ }^{3}$ See "Record of Policy Actions of the Federal Open Market Committee," Federal Reserve Bulletin (December 1982), pp. 761-66 and Daniel $L$. Thonton, "The FOMC in 1982: De-emphasizing Ml," this Review (June/July 1983), pp. 26-35.
}

The purpose of this article is to investigate whether the relationship between $M 1$ and nominal GNP has deteriorated and to examine the relative performance of $\mathrm{M} 1$ and $\mathrm{M} 2$ over recent years. ${ }^{4}$ While considerable research effort has been devoted to these questions already, we extend these efforts by (1) using a modified St. Louis-type equation that has performed well based on both in-sample and out-of-sample criteria, (2) considering both in-sample and out-of-sample performances of $\mathrm{M} 1$ and $\mathrm{M} 2$, (3) examining the role of the non-M 1 components of M2 separately, and (4) extending the sample period to include the two most recent financial innovations. ${ }^{5}$

\section{MONETA

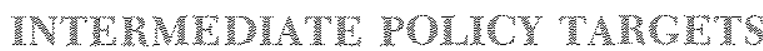

In order for a monetary aggregate to be an appropriate intermediate policy target, there must be a predictable relationship between it and income. ${ }^{6}$ To see this, note that the chain of causality for monetary policy runs from the instruments of monetary control to the in-

\footnotetext{
${ }^{4}$ We should note at the outset that we do not see this as a theoretical debate. The innovations of the past three years could have affected the income and interest elasticities of various financial assets so as to alter the usual relationships between these assets (or simple sum aggregates of these assets, such as $\mathrm{Ml}$ and M2) and nominal income. Thus, we believe that the issue is essentially empirical.

${ }^{5}$ For the specification of this modified St. Louis equation, see Dallas S. Batten and Daniel L. Thornton, "Polynomial Distributed Lags and the Estimation of the St. Louis Equation," this Review (April 1983), pp. 13-25.

${ }^{6}$ It is argued at times that this link must be stable as well as predictable. As a general rule, however, the less stable the relationship, the less predictable it is as well. Moreover, a stable relationship need not be a numerical constant as is often argued in the context of the money-GNP relationship.
} 


\section{Figure 1 \\ Chain of Causality for Monetary Control}

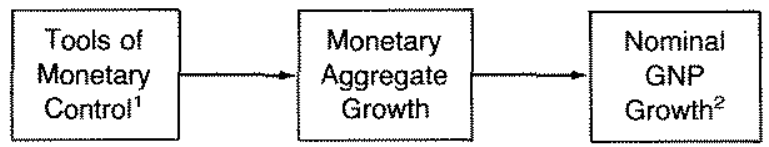

'Open Market Operations, changes in reserve requirements and the discount mechanism - the discount rate and the administra" tion of the discount window.

2The two main goals of policy, full employment and price level stability, are directly linked to nominal GNP growth.

termediate monetary target to the final goal, nominal GNP growth, as illustrated in figure 1. It is usually conceded that $\mathrm{M} 2$ is more difficult to control and, hence, the first link in the chain is stronger for an $\mathrm{M}$ target. ${ }^{7}$ Furthermore, there is evidence that the relalionship between the growth of the narrow aggregate and nominal GNP growth has been more stable historically, ${ }^{8}$

Recenty, however, some have argued that the relationship between $\mathrm{ML}$ and nominal income has become weaker than that between $\mathrm{M} 2$ and noome. In the context of figure 1 , those who now claim that $\mathrm{M2}$ is preferable to $M 1$ must be arguing implicity that the relationship between $\mathrm{M} 2$ and nominal $\mathrm{GNP}$ has strengthened sufficiently to ofset any policy problems that may result from the diffoulty of controling $\mathrm{M} 2$.

\footnotetext{
"For example see R. W. Hafer, "Much Ado About M2," this Review (October 1981), p. 13-18; and Patrick J. lawler, "The Large Monetary Aggregates as Intermediate Polny Targets, "Voice of the Federal Reserve Bank of Dallas (November 1981), pp. 1-13

"See Nater, "Much Ado kbout M2," Keth M. Carlson and Seott $E$. Hein, "Monetary Agyregates as Monetary Indicators," this Review (November 1980), [po. 12-21; and Mack Ott, "Money, Credit and velneity," this Review (May 1982), pp. 21-34.

"See, for example, Edward P. Foldessy, "New Bank Accounts May Force Fed To End Experiment in Monetarism," The Wall Street Joumal, December 28,1982 ; "The Money Mudile that Clouds the Recovery," Business Week (May 16, 1983), pp. 120-21, Vincent G. Salvo, "The Increasing Irrelevance of $\mathrm{Ml}$, "International Finarce, The Chase Manhattan Bank (Jme 6, 1983), pp. 4-5; and Aubrey G. Lanston \& Co. Inc., Newsletter (October 4,12 and 18, 1982). Similar anguments had been made prior to the fourth quarter of 1982. See, for example, Edward Yardeni, "Unlocking The Secrets of The Federal Reserve," E. F. Hutton Economics Alert (June 26, 1981); Irwin L. Kellner, "Breaking the Gridlock," The Manufacturers Hanover Economic Report (September 1981); William N. Griggs and Leonard J. Santow, The Schroder Report (August 17, 1981); and Trving Kristol, "The Tronble with Money," The Wall Street Journal, August 26, 1981
}

\section{The Relatonship Between Woner and GNP}

The relationship between a monetary aggregate and economic activity can be summarized by the following equation:

$$
\mathrm{MV}=\mathrm{Y}
$$

where $\mathrm{M}$ is a monetary aggregate, $\mathrm{V}$ is the income velocity of money (that is, the rate at which money changes hands in the purchase of final goods and services) and $Y$ is nominal GNP.

This relationship is viewed frequently in terms of growth rates. That is,

$$
\dot{\mathrm{M}}+\dot{\mathrm{V}}=\dot{\mathrm{X}}_{2}
$$

where the dots over each variable indicate compounded annual growth rates. From this representation, it is clear that the predictability of the relationship between a change in money growth and a subsequent change in GNP growth depends crucially on the predictability of the rate of growth of velocity.

For the past two decades, M1 velocity has been growing at an average rate of approximately 3 percent while, on average, M2 velocity has not grown at all. This is illustrated by chart 1 , which contains the fourquarter growth rates of M1 and M2 velocities. The time path of MI velocity growth oscillates around 3 percent, and the path of M2 velocity growth fluctuates around zero. During the past year and a hall, however, the growth of each of these velocities has declined dramatically. As a result, the link between these aggregates and GNP appears to have become weaker. Because the behavior of both velocities have been so similar, however, casual observation is insufficient to determine which of these relationships has deteriorated more.

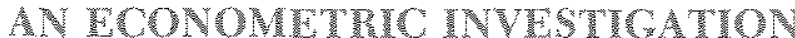

An econometric analysis of the relationship between money growth and economic activity involves the use of a version of the St. Louis equation. The St. Lonis equation was developed to investigate the impact of monetary and fiscal actions on nominal economic activity (measured by the growth of nominal GNP). The equation usually is written as:

(1) $\dot{X}_{t}=\alpha_{0}+\sum_{i=0}^{J} \beta_{i} \dot{M}_{t-i}+\sum_{i=0}^{K} \gamma_{i} \dot{G}_{t-i}+\varepsilon_{t}$,

where $\dot{\mathrm{Y}}, \dot{\mathrm{M}}$ and $\dot{\mathrm{G}}$ are the compounded annual growth rates of $\mathrm{GNP}$, a monetary aggregate and highemployment government expenditures, respectively. 


\section{Growth Rates of M1 Velocity and M2 Velocity}

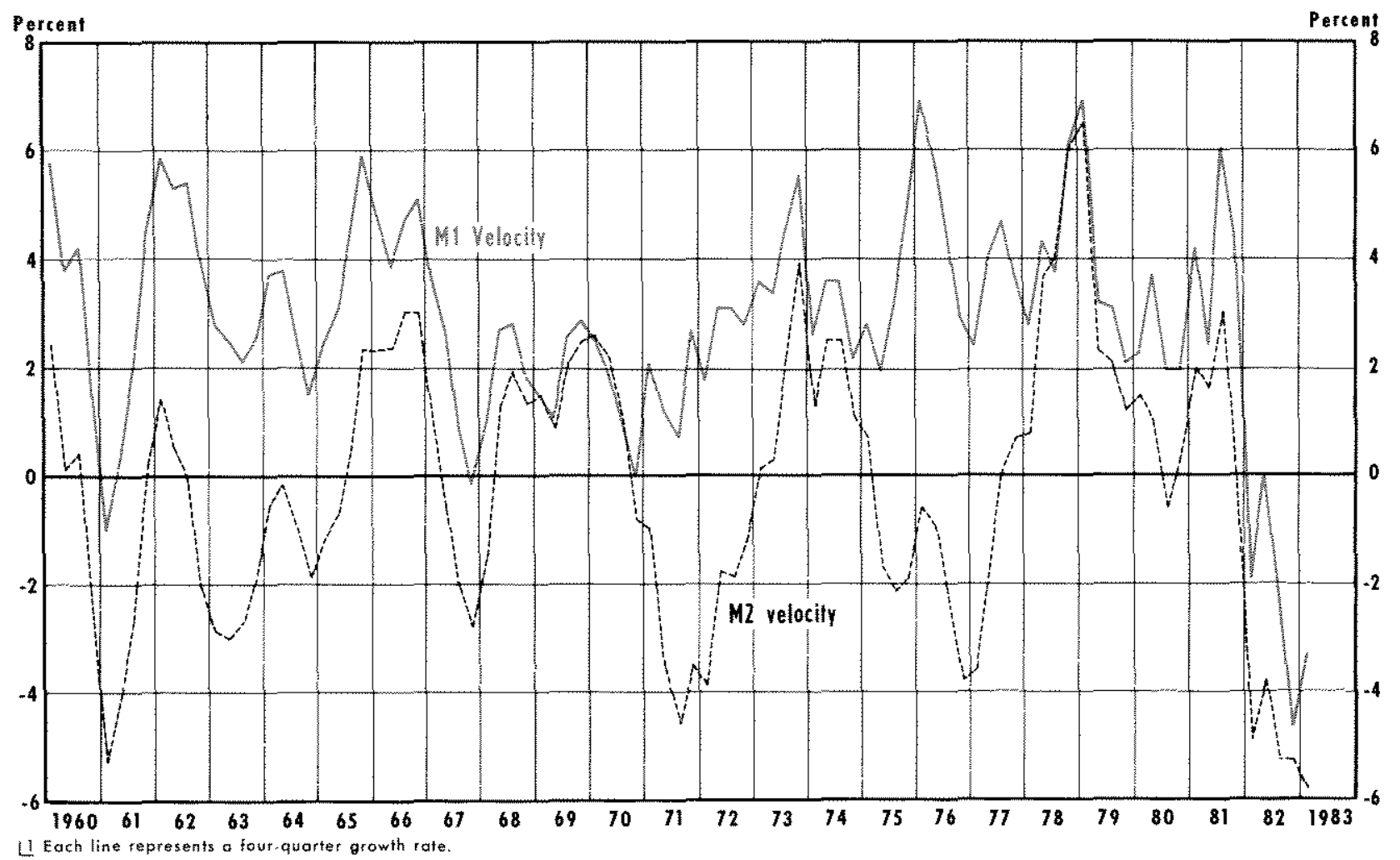

In this article, the appropriate lag lengths $(\mathrm{J}, \mathrm{K})$ are selected using an orthogonal regression procedure. ${ }^{10}$

Table 1 contains the results of estimating equation 1 over three sample periods - II/1962 to III/1982, II/ 1962 to IV/1982 and II/1962 to I/1983 - using either $\mathrm{M} 1$ or $\mathrm{M} 2$ as the monetary aggregate. Because the observed velocity behavior of both $\mathrm{M} 1$ and $\mathrm{M} 2$ have been unusual during the past two quarters (IV/1982 and $\mathrm{I} / 1983$ ), this stepwise angmentation of the sample period was employed to isolate the impact of these occurrences on the explanatory power of equation $1 .^{11}$

Several points of comparison are of interest. First, the M1 equation explains 48 percent of the variation in

\footnotetext{
${ }^{10}$ See Batten and Thornton, "Polynomial Distributed Lags." The lag lengths chosen are 10 for $M I$ and 9 for $G$ in the Ml equation, and 11 for $\mathrm{M} 2$ and 2 for $\dot{\mathrm{G}}$ if the $\mathrm{M} 2$ equation.

${ }^{11}$ Furthermore, an iterative analysis of several subsample periods was conducted beginning with the subsample period II/1962-IV/ 1979 and iterating (adding one quarter at each iteration) until the full sample period, II/1962-1/1983, was reached. The only indication of any deterioration in the explanatory power of either equation occurred when IV/1982 was added to the sample.
}

nominal GNP growth in the IV/1962-III/1982 period, while the M2 equation explains only 26 percent. The explanatory power of each equation, however, deteriorates substantially when the last two quarters of data are added. In relative terms, the decline in explanatory power is about the same for each aggregate; consequently, the absolute explanatory power of the M1 equation remains greater than that of the M2 equation when the last two quarters are included. Second, a 1 percentage-point change in the growth of either M1 or M2 ultimately leads to a 1 percentage-point change in GNP growth, regardless of the sample period. Finally, the cumulative impact of a change in high-employment government spending is not statistically significant in either equation for any sample period.

\section{In-Sample and Ontof-Sample Forecasts}

To investigate the possible impact of financial innovations and regulatory changes in-sample root mean square errors (RMSEs) are calculated for two sub- 


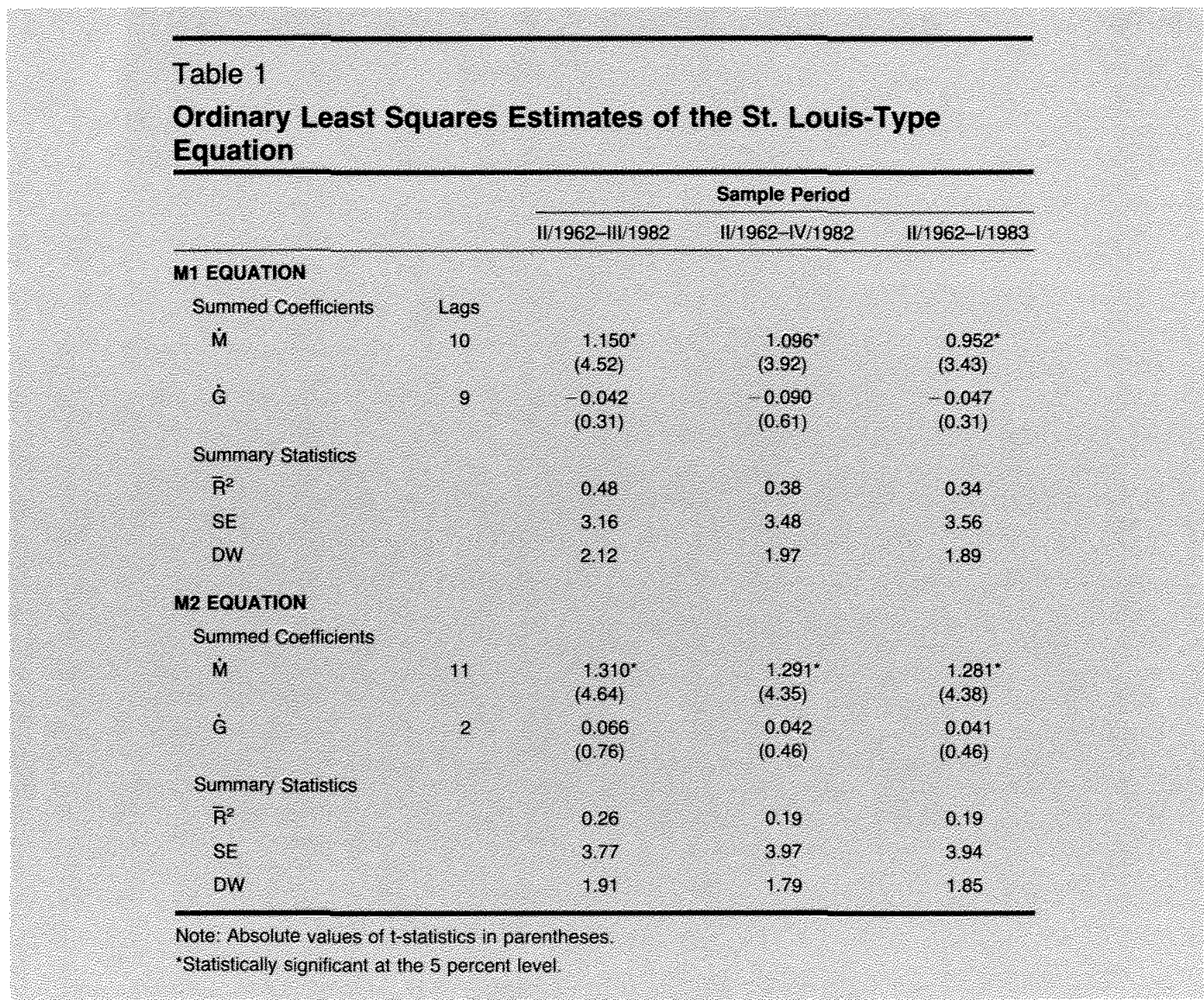

periods, before and after $\mathrm{I} / 1980 .{ }^{12}$ (These RMSEs are computed for each of the three estimations of the MI and M2 equations presented in table 1.) The latter period was chosen as the period within which the most important financial innovations and regulatory changes have occurred. These results are reported in table 2. They reveal two important facts: First, the in-sample explanatory performance of $\mathrm{M} 1$ during the $\mathrm{I} / 1980-\mathrm{III} /$ 1982 period actually improved somewhat compared with the period II/1962-IV/1979, while that of M2 deteriorated. Second, when the last two quarters are

${ }^{12}$ The in-sample RMSE is defined as:

$$
\sqrt{\frac{\sum_{i=1}^{n_{j}} e_{i}^{2}}{n_{j}}}
$$

where $e_{i}$ is the $i^{\text {th }}$ residuat and $n_{\mathrm{i}}$ is the number of observations in the $\mathrm{f}^{\text {th }}$ subsample. added to the second period, the performance of each aggregate deteriorates. The performance of $\mathrm{Ml}$, although still better than that of M2, does degenerate relative to that of M2. For example, the RMSE of the $\mathrm{Ml}$ equation for the $\mathrm{I} / 1980-\mathrm{J} / 1983$ period is 66 percent larger than that for the 1/1980-III/1982 period, while the same comparison for the M2 equation yields only a 9 percent increase in the RMSE.

A comparison of out-of-sample forecasts of the equations yielded results similar to those cited above. ${ }^{13}$ The

\footnotetext{
${ }^{13}$ Since the imposition of polynomial restrictions tends to smooth the distributed Iag weights and, thus, tends to improve the accura$c y$ of out-of-sample forecasts, these restrictions are imposed in both of the ont-of-sample experiments. The appropriate polynomial degrees are chosen using the methodology presented in Batten and Thornton, "Polynomial Distributed Lags." The degrees selected are 6 for $M I$ and 3 for $\dot{G}$ in the MI equation, and 5 for $\mathrm{M} 2$ in the M2 eguation; no polynomial restrictions are imposed on $\dot{G}$ in the $\mathrm{M} 2$ equation.
} 


\section{Table 2}

\section{In-Sample Root Mean Square Errors}

\begin{tabular}{|c|c|c|}
\hline \multirow[b]{2}{*}{ Pertod } & \multicolumn{2}{|c|}{ Equation } \\
\hline & $\mathrm{MI}$ & N2 \\
\hline 111962 W/1979 & 2,73 & 3.09 \\
\hline $11980+111982$ & 250 & 486 \\
\hline $111962-111979$ & 2.82 & 3.12 \\
\hline 11980.111908 & 3.77 & 5.50 \\
\hline W/ 1962 W/1979 & 281 & 3.12 \\
\hline $1 / 1980-1 / 1980$ & $4 \longdiv { 1 6 }$ & 5.32 \\
\hline
\end{tabular}

experiment conducted was to estimate each equation over the period IU/1962-IV/1979 and to forecast GNP growth to the end of the sample period. The out-ofsample RMSEs were calculated for three forecast periods - I/1980 to III/1982, I/1980 to IV/1982 and I/1980 to I/1983 - to demonstrate the impact that the last two quarters have on the forecasting accuracy of each equation. These results are reported in table 3 , and the individual errors are presented in chart 2 . The evidence indicates that, until the last two quarters, the M1 equation was more accurate in out-of-sample forecasting. When the last two quarters are included, however, the performance of $\mathrm{Ml}$ deteriorates significantly while that of $\mathrm{M} 2$ remains essentially unchanged. In fact, the initial relative success of the M1 equation vanishes completely when the last two quarters are considered.

These results reveal that the link between $\mathrm{Ml}$ growth and GNP growth remained strong up to the fourth quarter of 1982 . Thus, the contention that this relationship had deteriorated prior to the unusual occurrence of IV/1982 appears to be without substance. ${ }^{14}$ Both the in-sample and out-of-sample performances of the $\mathrm{Ml}$ equation are considerably better than those of the M2 equation. Thus, there is no evidence to support the contention that the relationship between M2 and income became stronger relative to that of $\mathrm{Ml}$ and income before IV/1982. The performance of M1, however, appears to be more adversely affected by the developments of the last two quarters. Even though there is evidence to indicate a recent deterioration in the M1-GNP relationship relative to the M2-GNP re-

\footnotetext{
${ }^{14}$ Toida and Gavin also find that M1 is preferable to M2 as an intermediate target. See Mitsuru Toida and William T. Gavin, "Non-nested Specification Tests and the Intermediate Target For Monetary Policy," Federal Reserve Bank of Cleveland Working Paper No. 8301 (June 1983).
}

Table 3

Out-of-Sample Root Wean Square Errors

\begin{tabular}{|c|c|c|}
\hline \multirow[b]{2}{*}{ Foreeast Petiod } & \multicolumn{2}{|c|}{ Equation } \\
\hline & MI & $m_{2}$ \\
\hline 11980 1111982 & 4.57 & 5.85 \\
\hline $11980-1 / 1982$ & 700 & 6.22 \\
\hline $111980-11983$ & 6.93 & 599 \\
\hline
\end{tabular}

lationship, this period is too short to ascertain whether this change is temporary or permanent.

\section{Andlysis of the Non-M \\ Components of $\mathrm{M}^{2}$}

By definition, M2 contains M1 plus certain other financial assets. ${ }^{15}$ Thus, implicit in the argument that $\mathrm{M} 2$ is preferable to $\mathrm{M} 1$ is the assumption that the non-M1 components of $\mathrm{M} 2(\mathrm{NMI})$ provide additional explanatory power over that of M1 alone. Furthermore, the non-MI components of M2 have characteristics which differ, in some cases markedly, from those of M1. Consequently, the marginal impacts of the MI and the non-M1 components of $\mathrm{M} 2$ upon economic activity may vary significantly. ${ }^{16}$ In order to capture the possibility of this differential impact, the growth of the non-M1 components of M2 is included separately with the growth of M1 in equation 1. Estimates from this augmented equation are given in table 4 for the three sample periods used previously. ${ }^{17}$

The inclusion of the non-MI components has little effect on the performance of the equation: the standard errors and adjusted $R^{2}$ s are about the same for comparable sample periods. More importantly, neither the hypothesis that the cumulative impact of the growth of the non-MI components is zero nor the joint hypothesis that all of these coefficients are zero can be re-

\footnotetext{
${ }^{15}$ These other assets are savings (including MMDAs) and small denomination time deposits at all depository institutions, overnight reptrchase agreements at commercial banks, overnight Eurodollars held by U.S. residents other than banks at Caribbean branches of member banks and balances of money market mutual funds (general purpose and broker/dealer).

${ }^{16}$ The marginal infuences of both sets of components are assumed implicitly to be the same in the estimation of the $\mathrm{M} 2$ equation because the coefficients of both sets are constrained to be identical.

${ }^{17}$ The lag lengths selected for the augmented equation are 10 for M1, 9 for $\mathrm{G}$ and 11 for NM1.
} 
Chant 2

Out-of-Sample Forecast Errors of Alternative St. Louis-Type Equation Specifications Acteal minus Predicted Values

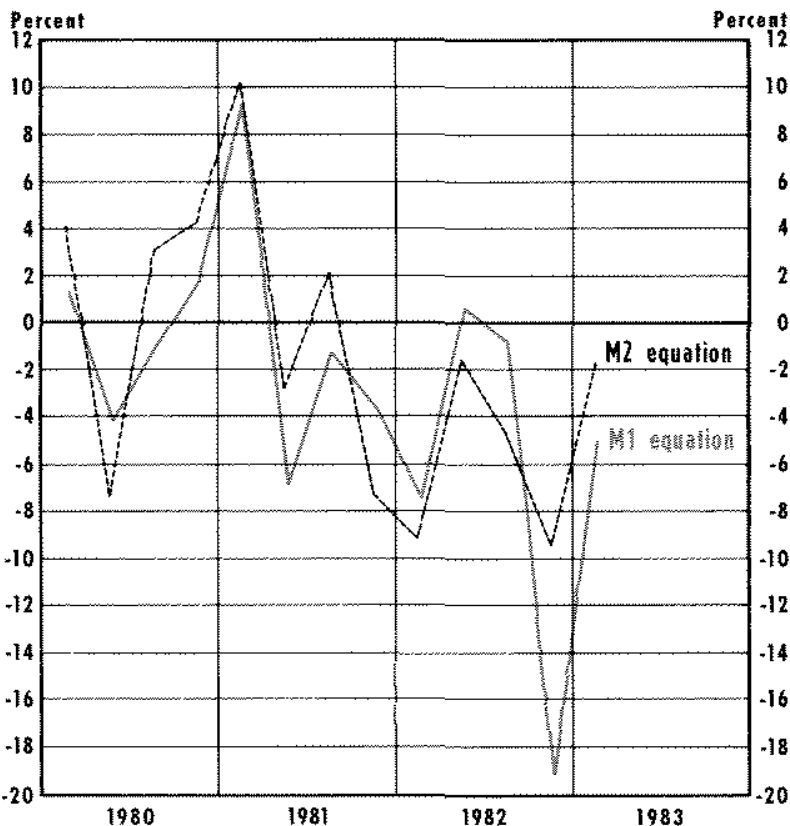

In-Sample Residuals of Alternative

St. Louis-Type Equation Specifications Actual minus Predicted Values

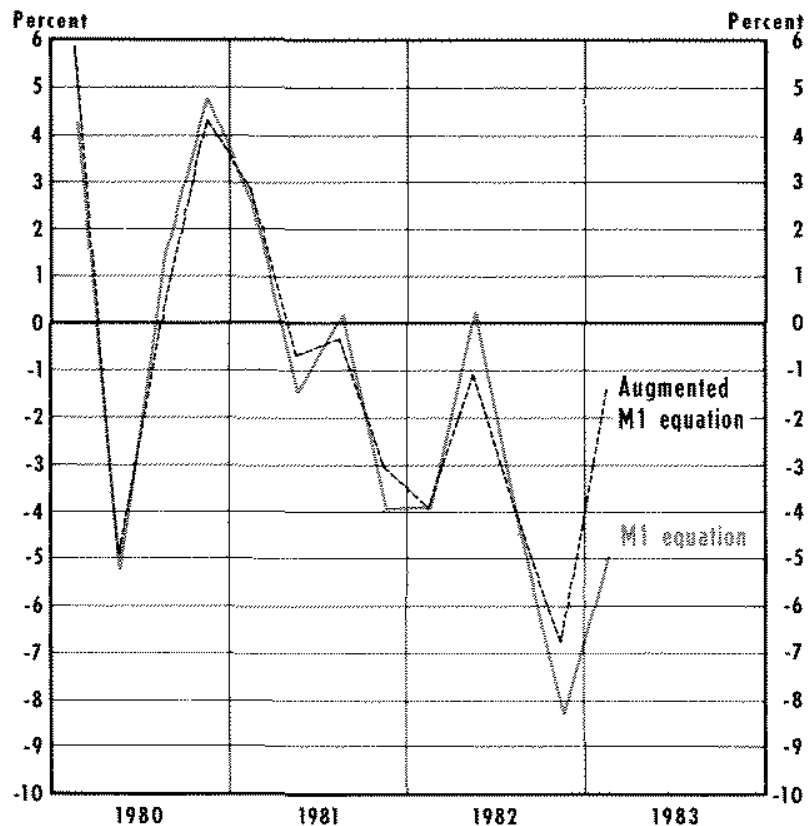

Table 4

Ordinary Least Squares Estimates of the Augmented St. Louis-Type Equation

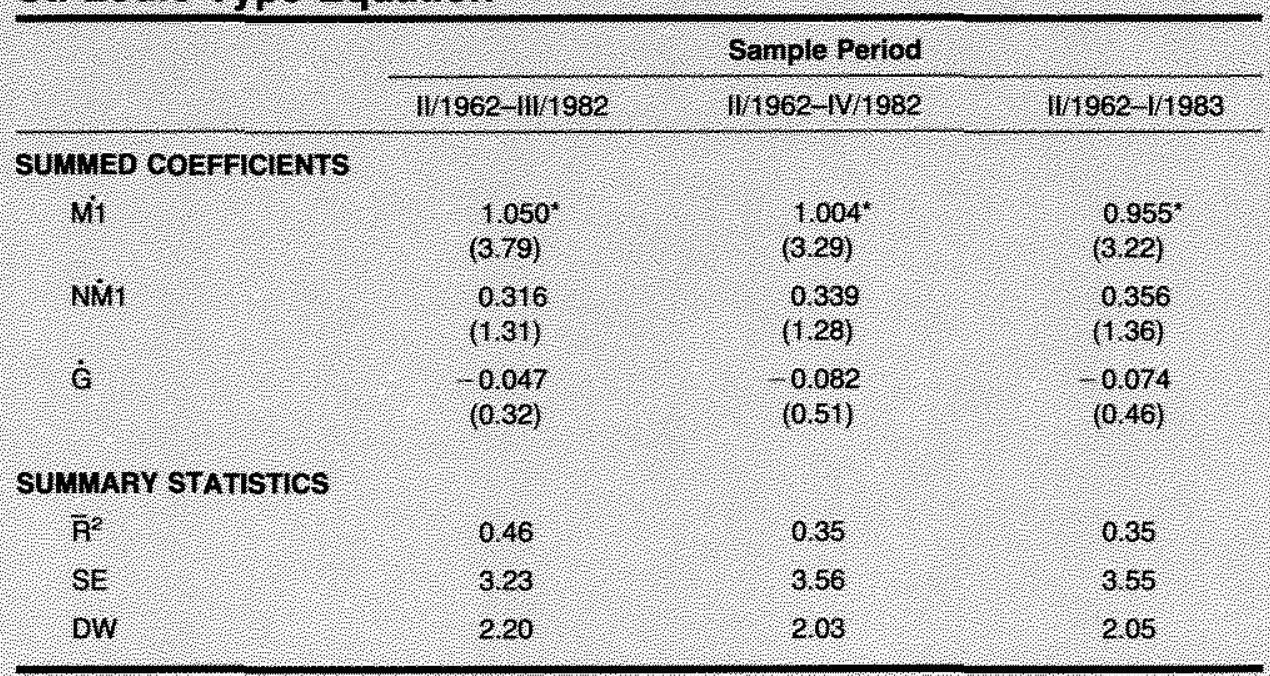

Note. Absolute values of 1 statistics in parentheses.

statistically sgniticant at the 5 percent level. 
jected at conventional significance levels during any of the three periods. ${ }^{18}$ Thus, the non-Ml components of M2 provide no additional power over M1 alone in explaining the variation of nominal GNP.

A closely related issue concerns whether the explanatory power of the non-M 1 components of M2 has improved as financial innovation has progressed. Chart 3 contains the in-sample residuals of the M1 equation and the augmented $M 1$ equation for the period $1 / 1980$ U/1983. If the additional explanatory power of the nonM1 components has improved during this period, one would expect to see the residuals of the augmented M1 equation becoming smaller relative to those of the initial M1 equation. The residuals of the augmented M1 equation do appear to be smaller than those of the M1 equation for the last three quarters. In other words, while these results provide only preliminary evidence, they do indicate that the performance of the non-MI components may have improved during the past two or three quarters.

\section{SUMMARY AND CONCLUSONS}

Financial innovation in the 1980s has led many to believe that the relationship between $\mathrm{Ml}$ growth and GNP growth has deteriorated relative to that between M2 growth and GNP growth. Although this is a con-

${ }^{18}$ The F-statistics calculated to test the hypothesis that all of the coefficients of $\mathrm{NMI}$ are zero in each of the three periods are 0.77 , 0.76 and 1.06, respectively, well below the critical value of 1.95 at the 5 percent significance level. ceptual possibility, an empirical investigation provides mixed support for this contention. It is clear that, within the framework of the version of the St. Louis equation presented here, MI growth explains more of the variation of nominal GNP growth than M2 growth and that there was no marked deterioration in the Ml-GNP relationship prior to the fourth quarter of 1982.

Drawing conclusions from summary statistics of explanatory power, however, confuses past with present performance. An analysis of in-sample and out ofsample forecasting errors reveals that the relative success of M1 has been due primarily to its past performance, not its present one. In particular, the occurrences of the past two quarters have had a substantially larger impact on the relationship between $\mathrm{MI}$ and nominal GNP than that between $\mathrm{M} 2$ and GNP. ${ }^{19}$

While this evidence should promote continued review of the relative merits of $\mathrm{M} 1$ and $\mathrm{M} 2$, it does not seem sufficient, at present, to conclude that M1 should be de-emphasized as an intermediate target of monetary policy. If subsequent empirical studies provide more conclusive evidence to support this tentative finding, then policymakers should consider changes that will enhance their ability to control M2.

\footnotetext{
${ }^{19}$ It should be noted that even though recent financial innovations and deregulation have motivated this study, the findings do not necessarily indicate that these innovations and regulatory changes have been the cause of the results obtained. In fact, much of the innovation and deregulation that has occurred predated the time period during which the changes in explanatory power have been identified
}

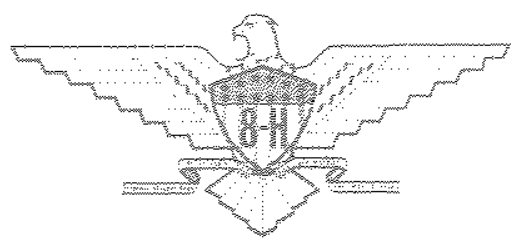

